REVIEW

\title{
Chemokines in joint disease: the key to inflammation?
}

J J Haringman, J Ludikhuize, P P Tak

Targeting chemokines and/or chemokine receptors appears to be an intriguing new approach to treating chronic inflammatory disorders like rheumatoid arthritis, inflammatory bowel diseases, multiple sclerosis, and transplant rejections. The involvement of chemokines and chemokine receptors in inflammatory joint diseases, the in vitro and in vivo characteristics of the chemokine family in inflammatory joint disease, and initial clinical data on chemokine blockade in patients with rheumatoid arthritis suggest that targeting the chemokine and chemokine receptor family might provide a new, promising antirheumatic strategy.

See end of article for authors' affiliations

Correspondence to: Dr P P Tak, Division of Clinical Immunology and Rheumatology, F4-218, Department of Internal Medicine, Academic Medical Centre/University of Amsterdam,

Meibergdreef 9 , NL-1 105

AZ Amsterdam, The

Netherlands; p.p.tak@

amc.uva.nl

Accepted 10 March 2004 Published online first 13 April 2004
$\mathrm{R}$ heumatoid arthritis (RA) is a chronic inflammatory disease that affects synovial tissue (ST) in multiple joints. Although its aetiology is still unknown, RA is thought of as an autoimmune disease. Severe morbidity and structural damage of joints caused by chronic inflammation requires early and effective treatment. ${ }^{1}$ The inflammatory process is characterised by infiltration of leucocytes in ST and the synovial fluid (SF) in the joints. A wealth of information now exists demonstrating that this process is mediated by the coordinated action of a variety of inflammatory mediators. Leucocytes adhere to the activated endothelium, leading to migration across the endothelial barrier into the $\mathrm{ST}^{2}$ A complex network of adhesion molecules and chemokines coordinate cell migration, by working in concert to induce an inflammatory response. $^{34}$ Investigators have recently extended initial observational studies to explore the role of chemokines and chemokine receptors in the pathogenesis of inflammatory joint disease.

As the clinical management of RA is difficult, there is a need for the development of a broader range of treatments targeting specific points of the complex pathogenetic network underlying RA. The chemokine and chemokine receptor families may provide intriguing targets for innovative treatment of RA and other chronic inflammatory disorders by the use of biological agents or targeted small molecules.

\section{CHEMOKINES}

Chemokines are a specialised family of small $(8-10 \mathrm{kDa})$ structurally related proteins that function as potent mediators of inflammation by their ability to recruit and activate specific leucocyte subpopulations. ${ }^{56}$ The members of the chemokine family can be distinguished from classical chemoattractant molecules (for instance, complement fragment peptides C3a and $\mathrm{C} 5 \mathrm{a}$, and lipid molecules such as leucotriene $\mathrm{B}_{4}$ and platelet activating factor) by their shared structural similarities. Chemokines have four conserved cysteine residues that form disulphide bonds, which are critical for the tertiary structures of these proteins. ${ }^{78}$

The chemokine family is organised into four subfamilies according to the position of the first two cysteines. The two major subclasses include the CC chemokines where the cysteines are adjacent and the CXC chemokines where the cysteines are separated by one amino acid. The CXC chemokines mainly act on neutrophils and lymphocytes, whereas the CC chemokines mainly act on monocytes and lymphocytes without affecting neutrophils. ${ }^{6}$

At least two chemokines do not fit into this classification. Lymphotactin is a chemokine, which lacks cysteines one and three of the typical chemokine structure (C-) and is a potent attractant for $\mathrm{T}$ lymphocytes, but not for monocytes. ${ }^{9}$ Fractalkine is a membrane bound glycoprotein, in which the first two cysteine residues are separated by three amino acids $(\mathrm{CXXXC}){ }^{10}$ These two chemokines may represent additional families.

\section{"Four chemokine subfamilies are mediators} of inflammation"

The discovery that certain chemokine receptors (CCR5 and CXCR4) are important co-receptors for HIV entry in lymphocytes gave a strong impulse to both basic research and to the development of new therapeutic agents targeting chemokine receptors.

One of the most commonly suggested characteristics of chemokines is the redundancy of the system. Redundancy occurs by having multiple ligands for each chemokine receptor and multiple receptors for each chemokine ligand, leading to the generation of multiple pathways directing similar cellular responses. This is discussed in more detail below.

\section{NOMENCLATURE OF CHEMOKINES}

To date more than 50 different human chemokines have been identified. Initially, chemokines

Abbreviations: IL, interleukin; MCP, monocyte chemoattractant protein; OA, osteoarthritis; PsA, psoriatic arthritis; RA, rheumatoid arthritis; SF, synovial fluid; ST, synovial tissue; TNF $\alpha$, tumour necrosis factor $\alpha$ 
were named according to their distinctive functions, for instance monocyte chemoattractant protein (MCP-1) or regulated upon activation normal $\mathrm{T}$ cell expressed and secreted (RANTES). The fact that the same chemokine was given multiple names by different groups (for instance HCC$2=$ Lkn-1 = MIP-1 $\delta$ ) made the already large and complex family even more complex. Moreover, additional research has shown that some chemokines have more functions than initially described and, therefore, their original names might suggest limited function. For instance MCP-1, a CC chemokine initially identified as a monocyte-specific chemoattractant, has also been shown to attract activated $\mathrm{T}$ cells, NK cells, and basophils. ${ }^{11}$ Besides attracting inflammatory cells,

Table $1 \mathrm{CXC}, \mathrm{C}, \mathrm{CX}_{3} \mathrm{C}$, and $\mathrm{CC}$ chemokine/receptor families. Adapted/modified from R Thorphe, J Immunol Methods 2002;262:1-3

\begin{tabular}{|c|c|c|}
\hline $\begin{array}{l}\text { Systemic name } \\
\text { ligand (L) }\end{array}$ & Common name ligand & $\begin{array}{l}\text { Systemic name } \\
\text { receptor (R) }\end{array}$ \\
\hline \multicolumn{3}{|c|}{ CXC Chemokine/receptor family } \\
\hline CXCL1 & GRO $\alpha / M G S A-\alpha$ & CXCR2>CXCR 1 \\
\hline $\mathrm{CXCL2}$ & GRO $\beta / M G S A-\beta$ & CXCR2 \\
\hline CXCL3 & GRO $\gamma / M G S A-\gamma$ & CXCR2 \\
\hline CXCL4 & PF4 & Unknown \\
\hline CXCL5 & ENA-78 & CXCR2 \\
\hline CXCL6 & GCP-2 & CXCR1, CXCR2 \\
\hline CXCL7 & NAP-2 & CXCR2 \\
\hline CXCL8 & IL8 & CXCR1, CXCR2 \\
\hline CXCL9 & Mig & CXCR3 \\
\hline CXCL10 & IP-10 & CXCR3 \\
\hline CXCL11 & I-TAC & CXCR3 \\
\hline CXCL12 & SDF-1 $\alpha / \beta$ & CXCR4 \\
\hline CXCL13 & $\mathrm{BCL}$ & CXCR5 \\
\hline CXCL14 & BRAK/bolekine & Unknown \\
\hline (CXCL15) & Unknown & Unknown \\
\hline CXCL16 & & CXCR6 \\
\hline \multicolumn{3}{|c|}{ C Chemokine/receptor family } \\
\hline $\mathrm{XCL1}$ & $\begin{array}{l}\text { Lymphotactin/SCM-1 } \alpha / \\
\text { ATAC }\end{array}$ & XCR1 \\
\hline $\mathrm{XCL} 2$ & $S C M-1 \beta$ & XCR1 \\
\hline \multicolumn{3}{|c|}{$\mathrm{CX}_{3} \mathrm{C}$ Chemokine/receptor family } \\
\hline $\mathrm{CX}_{3} \mathrm{CL} 1$ & Fractalkine & CX3CR1 \\
\hline \multicolumn{3}{|c|}{ CC Chemokine/receptor family } \\
\hline CCL1 & $1-309$ & CCR8 \\
\hline $\mathrm{CCL} 2$ & MCP-1/MCAF/TDCF & CCR2 \\
\hline CCL3 & MIP- $1 \alpha / L D 78 \alpha$ & CCR1, CCR5 \\
\hline CCL3L1 & LD78 $\beta$ & CCR1, CCR5 \\
\hline $\mathrm{CCL} 4$ & MIP-1 $\beta$ & CCR5 \\
\hline CCL5 & RANTES & CCR1, CCR3, CCR5 \\
\hline (CCL6) & Unknown & Unknown \\
\hline $\mathrm{CCL} 7$ & MCP-3 & CCR1, CCR2, CCR3 \\
\hline CCL8 & MCP-2 & CCR3, CCR5 \\
\hline (CCL9/CCL10) & Unknown & CCRI \\
\hline CCL11 & Eotaxin & CCR3 \\
\hline (CCL12) & Unknown & CCR2 \\
\hline $\mathrm{CCL} 13$ & MCP-4 & CCR2, CCR3 \\
\hline $\mathrm{CCL} 14$ & $\mathrm{HCC}-1$ & CCR1, CCR5 \\
\hline CCL15 & HCC-2/Lkn-1/MIP-1 $\delta$ & CCR1, CCR3 \\
\hline CCL16 & HCC-4/LEC/LCC-1 & CCR1, CCR2 \\
\hline CCL17 & TARC & CCR4 \\
\hline CCL18 & DC-CK $1 /$ PARC/AMAC- 1 & Unknown \\
\hline CCL19 & 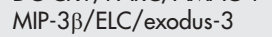 & CCR7 \\
\hline CCL2O & MIP- $3 \alpha /$ LARC/exodus- 1 & CCR6 \\
\hline $\mathrm{CCL} 21$ & $\begin{array}{l}\text { 6-chemokine/SLC/ } \\
\text { exodus-2 }\end{array}$ & CCR7 \\
\hline $\mathrm{CCL} 22$ & $\mathrm{MDC} / \mathrm{STCP}-1$ & CCR4 \\
\hline $\mathrm{CCL} 23$ & MPIF-1/CK $\beta 8 / C K \beta 8-1$ & CCRI \\
\hline $\mathrm{CCL} 24$ & Eotaxin-2/MPIF-2 & CCR3 \\
\hline $\mathrm{CCL} 25$ & TECK & CCR9 \\
\hline CCL26 & Eotaxin-3 & CCR3 \\
\hline $\mathrm{CCL} 27$ & CTACK/ILC & CCR10 \\
\hline $\mathrm{CCL} 28$ & MEC & CCR3/CCR10 \\
\hline
\end{tabular}

MCP-1 also plays a part in $\mathrm{T}$ cell differentiation and angiogenesis..$^{12}$

Therefore, a new nomenclature has been proposed. The system is based on the structural homology of different subgroups. Thus, chemokines can be divided into CXC, CC, CXXXC, and XC chemokines. For the ligands an $\mathrm{L}$ and a number are added (for example, MCP-1 is CCL2) and for the receptors an $\mathrm{R}$ and a number (for example, CCR1, CCR2 etc.) (table 1)..$^{14-16}$

\section{HOMOEOSTATIC CHEMOKINES IN RA}

Chemokines promote the accumulation of leucocytes at the source of chemokine production in multiple ways (fig 1). This can be part of a homoeostatic process or an inflammatory reaction. Chemokines can be grouped into either homoeostatic/constitutive chemokines or inflammatory/inducible chemokines, although some may have a dual role depending on how they are produced. ${ }^{17-19}$

Homoeostatic chemokines are produced within the lymphoid tissues and they are involved in maintaining homoeostatic leucocyte traffic and cell compartmentalisation in these tissues under non-inflammatory conditions. ${ }^{20}{ }^{21}$ They also assist in controlling the specificity of memory cell subsets in specific tissues. ${ }^{22}{ }^{23}$ In RA the expression of certain homing chemokines in the inflamed synovium is associated with the formation of lymphocyte aggregates resembling germinal centres in lymphoid tissue. ${ }^{24}$ These structures can be found in about $20-30 \%$ of patients with RA. ${ }^{25} 26$ Although research describing expression of homoeostatic chemokines and their receptors in inflamed $\mathrm{ST}$ is still limited, some homing chemokines like CXCL13/BCA-1, the ligand of CXCR5, have been implicated in the formation of these ectopic lymphoid structures in rheumatoid ST. CXCL13/BCA-1 expression was detected predominantly in follicular dendritic cells in germinal centres. ${ }^{27}$

\section{"Chemokines promote leucocyte accumulation in many ways"}

For homing of immature dendritic cells into RA synovium, the ligand-receptor pair CCL20/MIP-3 $\alpha$-CCR6 appears to be critical. These cells are especially found in the intimal lining layer and perivascular infiltrates. ${ }^{28}$ CCL20/MIP-3 $\alpha$ can be detected at higher concentrations in SF of patients with RA than in controls. It is also a chemoattractant for T cells, B cells, and monocytes. ${ }^{29}{ }^{30}$ A recent report showed that immunodepleting CCL20/MIP-3 $\alpha$ resulted in an overall inhibition of monocyte chemotaxis of $40 \% .^{30}$ The homing of mature dendritic cells to the lymphocyte infiltrates is influenced by CCL19/MIP-3 $\beta$ and CCL21/6-chemokine, the ligands for CCR7. They are expressed in the perivascular lymphocyte infiltrates and the vascular endothelium and are thought play a part in the migration of CCR7+ mature dendritic cells into the synovium. ${ }^{28}$

Another homoeostatic receptor, CXCR4, may have a role in the active retention of $\mathrm{T}$ cells within the synovial compartment; its only ligand known so far, CXCL12/SDF-1, is expressed by synovial endothelial cells and synovial fibroblasts. ${ }^{32}$ Moreover, CXCL12/SDF-1 co-localises with the neoangiogenesis marker $\alpha_{v} \beta_{3}$ integrin and can modulate angiogenesis in in vivo assays in mouse models. ${ }^{33}$

The ligand/receptor pair CXCL16-CXCR6 seems to be especially involved in plasma cell recruitment to bone marrow and target tissues. ${ }^{34}$ Expression of CXCR6 has been described in RA and could also attract effector $\mathrm{T}$ cells, mediating Thl responses. ${ }^{35}$

As homoeostatic chemokines and their receptors may play an important part in the continuation of inflammation by the 


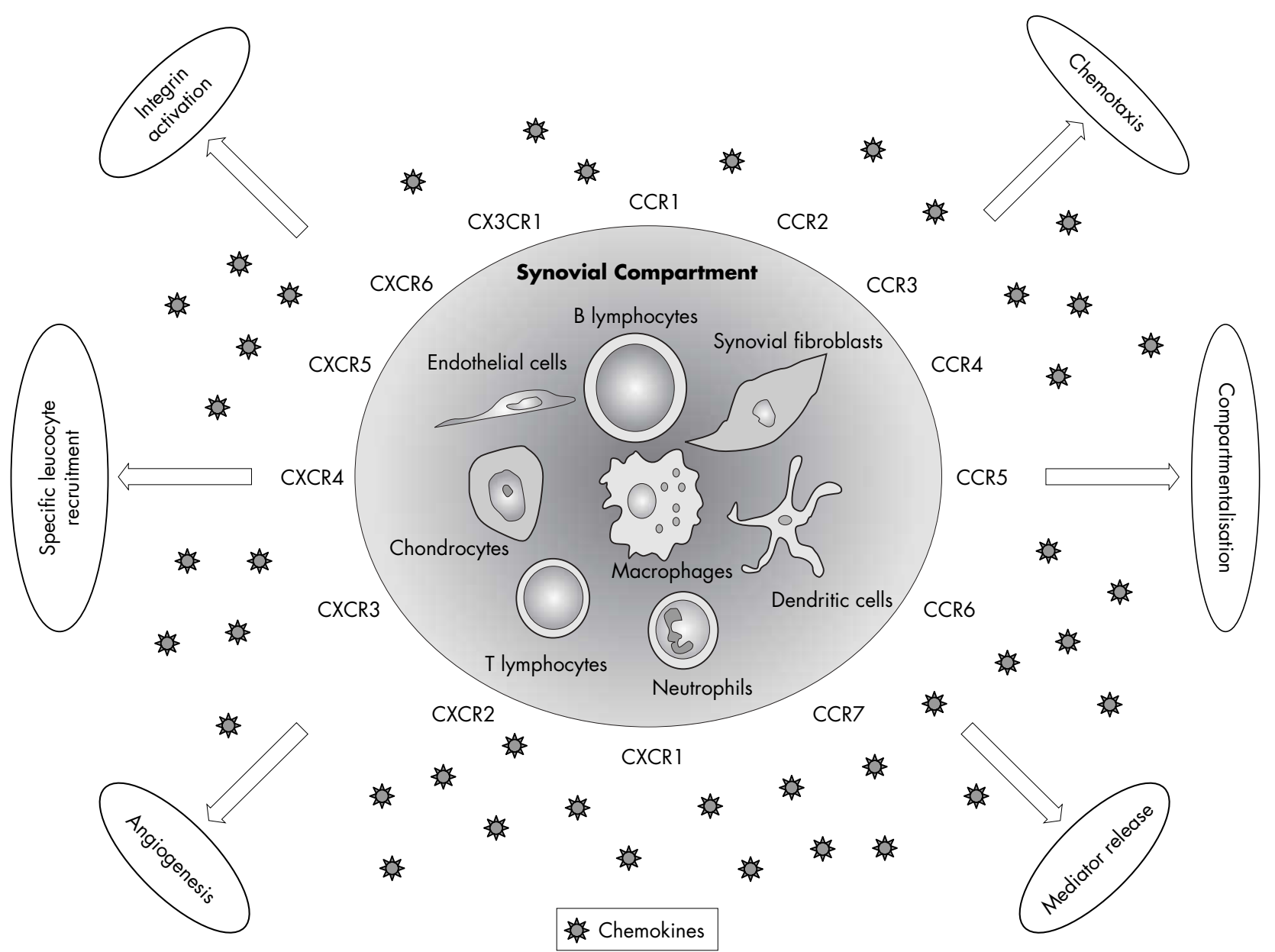

Figure 1 Overview of homoeostatic and inflammatory functional interactions of chemokines and their receptors in inflammatory joint disease.

formation of germinal centres and the sustained retention of cells in the synovial compartment, targeting these proteins might be an interesting new approach to the treatment of RA. Additional studies are needed to determine the therapeutic potential and safety of this approach. A concern might be that one does not want to interfere with the role of these molecules under non-inflammatory, physiological conditions. Clearly, most suitable potential targets still need to be defined.

\section{INFLAMMATORY CHEMOKINES IN RA}

In contrast with the homoeostatic chemokines, which are mainly involved in physiological processes, although some of them seem to play a dual role in inflammation, the inflammatory/inducible chemokines are preferentially produced in peripheral tissue at the sites of inflammation. At these sites they function to recruit neutrophils, monocytes, immature dendritic cells, B cells, and activated T cells. ${ }^{56}$ Several cell types, including endothelial, epithelial, and stromal cells as well as leucocytes, can produce inflammatory chemokines. Although many different cell types have the ability to produce inflammatory chemokines in the synovium, macrophages and fibroblast-like synoviocytes seem to be the most potent producers based upon in vitro experiments. ${ }^{36-39}$ Chemokine production is induced at high levels in response to inflammatory stimuli, such as lipopolysaccharide, interleukin (IL) l, and tumour necrosis factor $\alpha(\mathrm{TNF} \alpha)$. The inflammatory chemokines promote inflammation by an array of biological mechanisms ${ }^{13}$ (fig 1).
Leucocyte extravasation involves the sequential steps of selectin dependent initial attachment and rolling, G protein regulated activation, firm arrest through integrin binding to endothelial ligands, and transendothelial diapedesis. ${ }^{340}$ Chemokines participate in this process by providing a chemokine gradient and by activation of integrins. ${ }^{13}$

CXCL8/IL8 was among the first chemokines shown to be involved in leucocyte chemotaxis. ${ }^{41}$ In patients with RA, CXCL8/IL8 is present in high quantities in both ST and SF. ${ }^{42}{ }^{43}$ Of interest, CXCL8/IL8 protein and mRNA levels are specifically increased in clinically affected joints compared with clinically unaffected joints, suggesting a role in the development of clinical signs and symptoms. ${ }^{44}$ The notion that CXCL8/IL8 may be involved in the pathogenesis of RA is supported by the observation that a single intra-articular injection of CXCL8/IL8 can initiate arthritis in a time and dose dependent manner in rabbits. This is associated with an early increase in neutrophil numbers followed by an increase in mononuclear cells in the joints of these animals. ${ }^{43}$ In another study CXCL8/IL8 was also shown to have a major role in the trafficking of monocytes towards the ST. ${ }^{45}$

CCL2/MCP-1, a ligand of CCR2, has also been shown to have important chemotactic characteristics. CCL2/MCP-1 promotes transmigration of monocytes when present in a (soluble) gradient across an endothelial monolayer. ${ }^{46}$ CCL2/ MCP- 1 can also attract T cells, NK cells, and basophils. ${ }^{47}{ }^{48}$ ST macrophages are the dominant source of CCL2/MCP-1 production in RA, and levels of CCL2/MCP-1 are significantly increased in RA ST, SF, and peripheral blood. ${ }^{49}$ The possible role of CCL2/MCP-1 in monocyte migration towards the joint 
is supported by the observation that injection of CCL2/MCP-1 into rabbit joints leads to a clear increase in, especially, macrophage numbers. ${ }^{50}$

CCL5/RANTES (a ligand for CCR1, CCR3, and CCR5) is another chemokine implicated in leucocyte chemotaxis in RA. In RA fibroblast-like synoviocytes express CCL5/RANTES, and CCL5/RANTES gene expression is increased in SF mononuclear cells and peripheral blood mononuclear cells. ${ }^{51-53}$ CCL5/RANTES proved to be a potent inducer of migration of both monocytes and $\mathrm{T}$ lymphocytes in in vitro models. ${ }^{6}$ By blocking CCL5/RANTES using neutralising antibodies it was shown that in vitro migration towards SF and ST from patients with RA could be inhibited. ${ }^{54} 55$

CCR5, one of the receptors for CCL5/RANTES, is together with CXCR3 predominantly (but not exclusively) expressed by Thl cells. Thus, this receptor could have a crucial role in a Thl-type disease like RA. ${ }^{56-59}$ Examination of the expression of the ligands of CCR5 and CXCR3 in RA ST, SF, and peripheral blood showed that there is a chemotactic gradient between the serum and synovium for CCL3/MIP-1 $\alpha$, CCL4/ MIP-1 $\beta$, CXCL9/Mig, and CXCL10/IP-10, favouring migration into tissue..$^{6061}$

Other studies showed the importance of CCL3/MIP- $1 \alpha$ in neutrophil and macrophage chemotaxis into the synovial compartment. ${ }^{62}$ Besides a ligand for CCR5, this is also a ligand for CCRl. In addition to attracting neutrophils and macrophages CCL3/MIP- $1 \alpha$ is also involved in attracting lymphocytes to SF, although lymphocyte migration seems to be dependent on multiple chemokines. ${ }^{63}$

The ability to provide chemokine gradients and the ability to bind to synovial structures may vary between different chemokines. Only a subset of the chemokines appears to bind efficiently to structures in the extravascular space, which may be dependent on their glycosaminoglycan binding capacity, indicating that the formation of chemotactic gradients in tissues may be very complex. ${ }^{64}$ Although blockage of single chemokines may inhibit migration, the combination of several antibodies targeting different chemokines seems to be more effective in reducing the migratory activity towards the synovial compartment. ${ }^{63}$

Besides providing a functional gradient, chemokines can also promote chemotaxis by inducing a rapid but transient increase in adhesion of leucocytes to immobilised integrin ligands. ${ }^{65}{ }^{66}$ This can occur by two different mechanisms: up regulation of integrin affinity through conformational changes and changes in integrin avidity that occurs through integrin clustering. ${ }^{65}{ }^{67}$ Using in vitro flow chamber assays, it was shown that some of these chemokines could up regulate integrin function and then induce arrest and firm adhesion of rolling cells. For example, CXCL8/IL8 can induce adhesion of CXCR1 and CXCR2 expressing neutrophils; CCL2/MCP-1 may trigger adhesion through its receptor CCR2, and different memory lymphocyte subsets can adhere in response to ligands for CXCR3 (CXCL9/Mig and CXCL10/IP-10). ${ }^{68-70}$ Figure 2 shows the expression of CCR1, CCR2b, CCR5, CXCR4, CCL2/MCP-1, and CCL5/RANTES in the ST of a patient with RA.

\section{CYTOKINE-CHEMOKINE INTERACTIONS}

There is a complex relationship between inflammatory cytokines and chemokines.

Multiple studies have shown that a vast number of proinflammatory cytokines, like IL1, IL2, interferon $\gamma$, and TNF $\alpha$ can stimulate chemokine production by different cell types present in rheumatoid ST. ${ }^{36}{ }^{71-73}$ Macrophages may produce a broad variety of chemokines, including CC and CXC chemokines like CXCL8/IL8, CCL2/MCP-1, and CCL3/MIP- $1 \alpha^{42}{ }^{49} 62$ In addition, lymphocytes and fibroblastlike synoviocytes can produce various chemokines upon appropriate stimulation. ${ }^{36} 3774$ Conversely, chemokines may also stimulate cells to release inflammatory mediators including cytokines. Stimulation of fibroblast-like synoviocytes from patients with RA with CCL2/MCP-1, CCL5/ RANTES, and CXCL12/SDF-1 results, for instance, in enhanced production of IL6 and IL8. ${ }^{75}$ Similarly, CCL3/MIP$1 \alpha$ has been shown to stimulate the synthesis of ILl, TNF, and IL6 by murine peritoneal macrophages. ${ }^{76}$

A relationship between chemokines and matrix metalloproteinases (MMPs) has also been described. The interaction between CXCL12/SDF-1 and its receptor CXCR4 on chondrocytes may result in increased secretion of MMP-3, a cartilage matrix degrading enzyme. ${ }^{77}$ CCL2/MCP-1, CCL5/ RANTES, and CXCLI/GRO $\alpha$ were also shown to stimulate MMP-3 release by chondrocytes isolated from osteoarthritis (OA)articular cartilage samples. ${ }^{78}$

Although there is clear evidence that chemokines can stimulate various cell types in the joint to produce cytokines and MMPs, promoting synovial inflammation and joint degradation, the data are still limited.

\section{ANGIOGENESIS}

Angiogenesis, the process by which new capillaries are formed from existing vessels, is fundamental to a variety of physiological activities, such as wound healing and the female reproductive system. In addition, angiogenesis plays a part in pathological processes, including tumour growth and chronic inflammation. ${ }^{79}$ In RA, neovascularisation is one of the early changes in the ST, and in this complex, but coordinated, process chemokines are intimately involved. Chemokines may have either angiogenic or angiostatic properties. Initially, for CXC chemokines it was shown that this was dependent on the so called ELR motif, which is the sequence of three amino acids (Glu-Leu-Arg) near the $\mathrm{NH}_{2}$ terminus before the first cysteine. Chemokines containing this motif were thought to be angiogenic, whereas chemokines without this motif appeared to be angiostatic. ${ }^{80}$ CXCL8/ IL8 was the first chemokine with an ELR motif shown to have angiogenic properties. Other ELR-containing CXC chemokines with angiogenic features include CXCL5/ENA78 and $\mathrm{CXCLl} / \mathrm{GRO} \alpha$, whereas non-ELR chemokines like CXCL4/PF4 and the CXCR3 ligands CXCL9/Mig, CXCL10/IP10, and CXCL11/I-TAC are angiostatic. ${ }^{80-83}$ Although studies have shown that the CXCR3 ligands function as angiostatic mediators, in high concentrations they could in vitro also induce endothelial cell chemotaxis. ${ }^{84}$ There are more exceptions to the "ELR" rule, like the ELR negative chemokines CXCL12/SDF-1 and CXCL2/GRO $\beta$, which do have angiogenic features. ${ }^{85} 86$ Other chemokines with angiogenic properties lacking the ELR motif include the $\mathrm{CC}$ and $\mathrm{CX}_{3} \mathrm{C}$ chemokines CCL2/MCP-1 and $\mathrm{CX}_{3} \mathrm{CLl} /$ fractalkine..$^{87-89}$

It is also possible that the angiogenic or angiostatic involvement does not depend on the chemokine ligand, but on its receptor. Endothelial cells may express functional chemokine receptors, which can induce angiogenic signals, like CXCR2 and CXCR4. Alternatively, they may express receptors like CXCR3, which induce angiostatic signals. ${ }^{83} 90$ Although the role of chemokines and their receptors in angiogenesis is as yet not completely understood, it has become clear that they are not only involved in stimulating inflammation, but may also have inhibiting features.

\section{CHEMOKINES IN JOINT DISEASES OTHER THAN RA}

Although the vast majority of research on chemokines in inflammatory joint disease is focused on RA, it seems clear that chemokines and their receptors also have a role in other inflammatory arthropathies like OA and psoriatic arthritis (PsA). 


\section{CCR1}

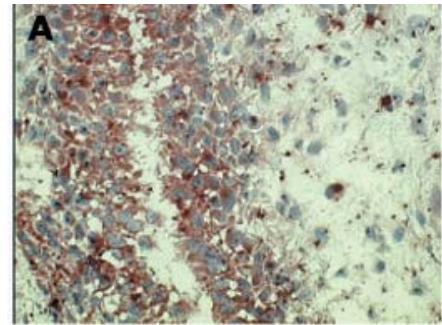

CCR5
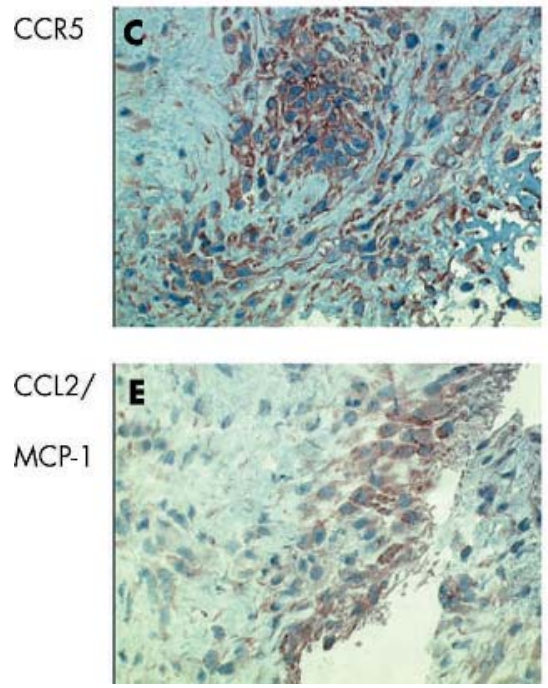
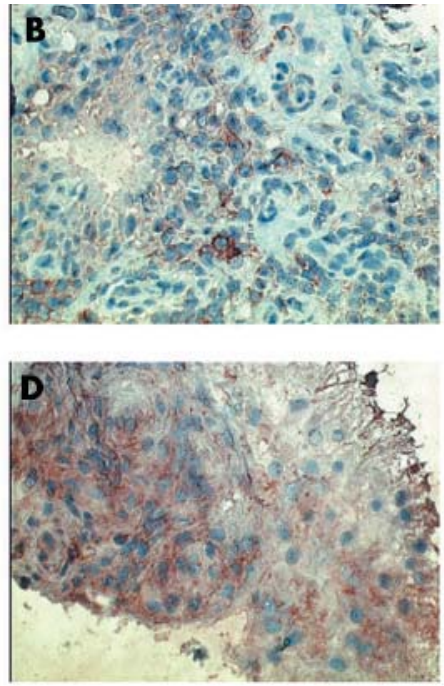

CXCR4

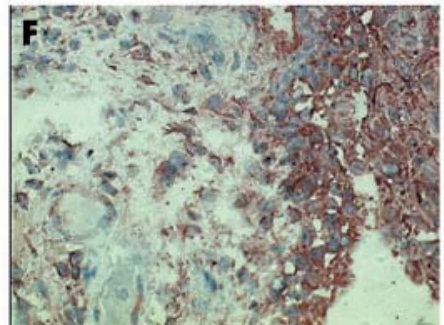

CCR2b

$\mathrm{CCL} 5 /$
RANTES

Figure 2 Expression of chemokine and chemokine receptor staining in RA ST. CCR1 positive cells are scattered throughout the synovium, and are expressed predominantly by macrophages. There is marked CCR1 expression in the intimal lining layer. CCR2b is expressed by macrophages, especially in the synovial sublining. CCR5 is expressed by both T lymphocytes and macrophages. CXCR4 is mainly expressed by T lymphocytes in the synovial sublining. CCL2/MCP-1, a ligand for CCR2 $b$ is almost exclusively expressed in the intimal lining layer. CCL5/RANTES, a ligand for CCR1, CCR3, and CCR5 is expressed in both the intimal lining layer and the synovial sublining. (Single stain peroxidase technique, positive staining in red/ brown, Mayer's haematoxylin counterstained, original magnifications $\times 400$ ).

In OA, traditionally considered a non-inflammatory arthropathy, synovial inflammation has been well documented. ${ }^{1-93}$ There is accumulating evidence suggesting the involvement of chemokines and their receptors in the disease process. Among others, CCL2/MCP-1 and CCL5/RANTES are expressed in both SF and ST of patients with OA. ${ }^{94-96}$ Fibroblast-like synoviocytes from patients with OA have the capacity to produce CXCL8/IL8, CCL2/MCP-1, CCL3/MIP- $1 \alpha$, and CCL5/RANTES. ${ }^{37} 5497$ Although most of the described chemokines and receptors appear to be expressed at higher levels in ST and SF in RA than in other inflammatory arthropathies, there might be at least one exceptionnamely, CCL4/MIP-1 $\beta$. It is found at significantly greater levels in the SF of patients with OA than in other forms of inflammatory arthritis like RA. ${ }^{98}$ CCL4/MIP- $1 \beta$, which is a ligand for CCR5, may be responsible for a substantial fraction of OA SF chemotactic activity for monocytes, particularly for activated monocytes.

In addition, chemokines and chemokine receptors are expressed by chondrocytes and, as mentioned earlier, interaction between chemokine receptors and their ligands may cause MMP-3 induction in chondrocytes. ${ }^{789} 100$ Compared with RA and PsA, OA cartilage appears to exhibit higher expression of the chemokine receptors CCR1, CCR3, CCR5, CXCR1, CXCR2, and CXCR3, but still lower than the cartilage of normal donors. ${ }^{101}$

In PsA CCL2/MCP-1, CCL5/RANTES, CXCL1/GRO $\alpha$, CXCL8/ IL8, CXCL9/Mig, as well as CCR2 and CCR5, have been described in both ST and SF. ${ }^{95}{ }^{102-104}$ CCR2 and CCR5 were also detected in the SF of patients with ankylosing spondylitis, reactive arthritis, Lyme arthritis, and gout. ${ }^{103}$
Evidently, chemokines and their receptors are present in the peripheral blood, synovial compartment, and cartilage in patients with arthritides other than RA. Although the level of expression may vary between the different forms of arthritis, none of the inflammatory chemokines or receptors appears specific for any of the conditions; presumably their presence reflects the effector mechanisms involved in the inflammatory process. This suggests that inhibition of the chemokine repertoire might not only be a useful strategy in the treatment of RA but also in other forms of inflammatory joint disease.

\section{ANIMAL MODELS}

In addition to in vitro studies suggesting the potential of reducing cell migration by inhibition of chemokines and chemokine receptors, animal models have been used to assess the value of the chemokine inhibitors in vivo. As animal models can be used to assess the role of several pathogenic factors at various stages of the disease, they provide a sophisticated tool for studying the relevance of chemokines and chemokine receptors.

Various chemokines have been described in arthritis models. MIP-2, the murine equivalent of CXCL8/IL8 has been detected in the joints of mice with collagen induced arthritis in the early stage of disease, whereas other chemokines like CCL5/RANTES and CCL3/MIP- $1 \alpha$ were present in early as well as late disease stages. ${ }^{105}$ In the rat adjuvant arthritis model it was shown that among different cytokines, the chemokines CCL3/MIP- $1 \alpha$ and CXCL5/ENA78-like protein are involved in the onset of arthritis and JE (CCL2/MCP-1) is involved in late phases of the disease. ${ }^{106}$ 
Chemokines and their receptors can be targeted in different ways, using neutralising antibodies, modified chemokines or small molecule receptor antagonists. Examples of targeted chemokines and receptors in animal models of arthritis include CCL2/MCP-1, CCL5/RANTES, CXCL5/ENA-78, CXCL10/IP-10, CXCR2, CXCR4, CCR2, and CCR5. ${ }^{107-115}$ Targeting CCL2/MCP-1 in rats or its receptor CCR2 in mice showed that both approaches reduced arthritis activity. In both models there was a reduction in macrophage infiltration and protection against joint destruction. ${ }^{107}{ }^{108}$ Treatment of rat adjuvant arthritis with a polyclonal antibody directed against human CCL5/RANTES resulted in clinical improvement and reduced cell infiltration and joint damage, while antibody treatment directed at CCL3/MIP- $1 \alpha$ in the same model did not influence the disease. ${ }^{109}$ It has also been shown that targeting the CXC chemokine CXCL10/IP-10 may inhibit leucocyte migration and induce an alteration in the Th1/Th2 balance in rats. ${ }^{111}$ Another successful example of chemokine blockade using antibodies is antihuman ENA-78 antibody treatment in rat adjuvant arthritis, which targets the CXC ligand CXCL5/ENA-78 like protein. This approach was effective when given before disease onset, but it could not modify the disease when administered after the development of clinical signs of arthritis. ${ }^{112}$

Of interest, several synthetic, non-peptide, highly specific chemokine receptor antagonists have been reported to be effective in animal models. AMD3100, a specific antagonist of the CXCR4 receptor, could delay the onset of arthritis and reduce the severity of symptoms in mice. Treatment with AMD3100 also led to a decrease in infiltration by mononuclear cells and neutrophils and a reduction in synovial tissue hyperplasia and pannus formation. ${ }^{113}$ Similarly, treatment with a selective non-peptide antagonist of CXCR2 (the receptor of CXCL8/IL8) in a rabbit arthritis model resulted in reduced neutrophil, monocyte, and lymphocyte counts in SF. ${ }^{114}$ Finally, a non-peptide CCR5 antagonist resulted in reduction of both incidence and severity of collagen induced arthritis by modulating T cell migration. ${ }^{15}$

Many of these studies clearly suggest that targeting migration of leucocytes by chemokine blockade might be feasible and that this approach could be used to ameliorate clinical signs of arthritis and inhibit joint destruction. Although in most reported studies chemokine blockade prevented arthritis, it appears to be more difficult to reduce established disease. ${ }^{112}$ Taken together, the available evidence suggests that specific inhibition of one chemokine or one chemokine receptor may have relevant clinical and biological effects in animal models, despite the redundancy of the system. Obviously, however, promising results in animal models need to be confirmed in human disease.

\section{HUMAN STUDIES}

Chemokine receptors are G protein coupled, seven transmembrane spanning receptors. Several small molecule antagonists targeting these receptors have recently been developed. ${ }^{116} 117$ To date only a few publications have described the effects of chemokine or chemokine receptor antagonism in patients with chronic inflammatory disease. It has been suggested in a review article ${ }^{118}$ that there was lack of efficacy of treatment in a phase II study using a monoclonal antibody against CXCL8/IL8 in patients with RA, but the full dataset has as yet not been published.

Recent work suggested the potential of treatment with a CCRl antagonist in patients with RA. ${ }^{116}{ }^{119}$ In a relatively small phase Ib study, patients were treated with a potent and selective antagonist for CCRl for 2 weeks, which was well tolerated. ${ }^{119}$ Analysis of ST samples showed a clear reduction in synovial inflammation in the active treated group compared with the placebo group. Cells capable of expressing the CCRl receptor were affected, whereas cells unable to express this receptor were not influenced by the treatment, confirming the specificity of the compound.

Although this study was not designed to determine clinical efficacy, one third of the patients in the active group fulfilled the ACR20 criteria for improvement (including one patient with an ACR50 response) already after 2 weeks of treatment, whereas there were no responders in the (small) placebo group. This study is the first in humans showing that chemokine antagonism might be feasible and suggesting that it is indeed possible to influence migration of inflammatory cells in a chronic inflammatory disease using a specific orally available chemokine receptor antagonist. Obviously, the clinical relevance needs to be confirmed in larger, well controlled clinical trials. The study with the CCRl antagonist adds to the rationale for such trials.

\section{REDUNDANCY OF THE CHEMOKINE SYSTEM}

Based upon in vitro data one might conclude that most of the chemokines have redundant or similar functions compared with other chemokines, although particular receptors are expressed by specific cells (for instance CXCRs mainly by neutrophils, and CCRs mainly by monocytes and lymphocytes). Examination of the in vivo data in animal models showed, as discussed above, that the production of chemokines is coordinated and that different chemokines function at distinct stages of disease evolution. Data from knockout models showed the effects of depletion of one particular chemokine or chemokine receptor-for instance, CCRI knockout mice were partially protected against experimental allergic encephalomyelitis compared with CCRl+/+ mice. ${ }^{120}$

The differences in the dynamic interactions between a ligand and receptor also imply distinct functions for different receptors. For instance CXCR1 and CXCR2, both expressed on neutrophils and both serving as receptor for CXCL8/IL8, respond differently to CXCL8/IL8 binding. CXCR1 is slowly internalised and rapidly recycled after binding, whereas CXCR2 is rapidly internalised, targeted for degradation, and reappears only slowly at the membrane after ligand activation. ${ }^{121}$

Many chemokines and chemokine receptors are expressed within the synovial compartment of patients with RA, which might suggest redundancy in chronic synovial inflammation. It should be noted, however, that differences in expression may also suggest distinct pathogenetic functions for various ligands and receptors. CCRl, for example, appears to be involved in the initial recruitment of monocytes from the circulation to the sites of inflammation, whereas CCR5 may be more important in the retention of cells within the synovial compartment. ${ }^{122}$

Increasing evidence suggests that the chemokine system functions in a delicately controlled manner with distinct as well as overlapping functions for individual chemokines and receptors, depending on the stage of the disease. The data from blocking studies in animal models provide evidence that redundancy of the system does not exclude beneficial clinical and biological effects of specific chemokine antagonism. On the other hand, it might even provide a safe background for therapeutic application of highly specific antagonists. The first report of the effects of treatment with a specific CCRl antagonist in RA confirms that inflammation might be decreased safely by specifically targeting one chemokine receptor. ${ }^{119}$

\section{CONCLUSION}

Clearly, a very sophisticated system exists, controlling the movement of leucocytes under physiological and pathological conditions. Chemokines and their receptors have an important role in this system not only by directing the migration of 
cells but also by controlling other important mechanisms like release of mediators of inflammation and angiogenesis. Despite the redundancy of the system, animal studies have shown the potential effect of specific antagonism of ligands and receptors in disease models, with apparently few side effects. The first human study with a small molecule serving as a chemokine receptor antagonist was recently performed in patients with RA and showed clear biological efficacy. Although biological treatments using neutralising antibodies or modified chemokines as receptor antagonists might provide effective treatments, the ideal therapeutic agent may be a small molecule antagonist which can be administered orally.

There are several caveats, however, that need to be recognised. Conceivably, it is necessary to use polychemokine antagonists ${ }^{117}$ or combine different chemokine antagonists ${ }^{63}$ to block specific chemokine pathways. Additionally, it is possible that some ligands may act as agonists at one receptor and as antagonists at others. ${ }^{123}$

In conclusion, although several questions remain to be answered, chemokine blockade may be a promising, innovative approach for treating chronic inflammation.

\section{Authors' affiliations}

J J Haringman, J Ludikhuize, P P Tak, Division of Clinical Immunology and Rheumatology, Academic Medical Centre/University of

Amsterdam, The Netherlands

\section{REFERENCES}

1 Lee DM, Weinblatt ME. Rheumatoid arthritis. Lancet 2001;358:903-11.

2 Oppenheimer-Marks N, Brezinschek RI, Mohamadzadeh M, Vita R, Lipsky PE. Interleukin 15 is produced by endothelial cells and increases the transendothelial migration of T cells in vitro and in the SCID mouse-human rheumatoid arthritis model in vivo. J Clin Invest 1998;101:1261-72.

3 Springer TA. Traffic signals for lymphocyte recirculation and leukocyte emigration: the multistep paradigm. Cell 1994;76:301-14.

4 Weber KS, von Hundelshausen P, Clark-Lewis I, Weber PC, Weber C. Differential immobilization and hierarchical involvement of chemokines in monocyte arrest and transmigration on inflamed endothelium in shear flow. Eur J Immunol 1999;29:700-12.

5 Baggiolini M. Chemokines in pathology and medicine. J Intern Med 2001;250:91-104

6 Luster AD. Chemokines-chemotactic cytokines that mediate inflammation. N Engl J Med 1998;338:436-45.

7 Rollins BJ. Chemokines. Blood 1997;90:909-28.

8 Fernandez EJ, Lolis E. Structure, function, and inhibition of chemokines. Annu Rev Pharmacol Toxicol 2002:42:469-99.

9 Kelner GS, Kennedy J, Bacon KB, Kleyensteuber S, Largaespada DA, Jenkins NA, et al. Lymphotactin: a cytokine that represents a new class of chemokine. Science 1994;266:1395-9.

10 Bazan JF, Bacon KB, Hardiman G, Wang W, Soo K, Rossi D, et al. A new class of membrane-bound chemokine with a CX3C motif. Nature 1997;385:640-4.

11 Gu L, Tseng SC, Rollins BJ. Monocyte chemoattractant protein-1. Chem Immunol 1999:72:7-29.

12 Luther SA, Cyster JG. Chemokines as regulators of T cell differentiation. Nat Immunol 2001;2:102-7.

13 Mackay CR. Chemokines: immunology's high impact factors. Nat Immunol 2001:2:95-101.

14 Zlotnik A, Yoshie O. Chemokines: a new classification system and their role in immunity. Immunity 2000;12:121-7.

15 Murphy PM, Baggiolini M, Charo IF, Hebert CA, Horuk R, Matsushima K, et al. International union of pharmacology. XXII. Nomenclature for chemokine receptors. Pharmacol Rev 2000;52:145-76.

16 Murphy PM. International Union of Pharmacology. XXX. Update on chemokine receptor nomenclature. Pharmacol Rev 2002;54:227-9.

17 Gerard C, Rollins BJ. Chemokines and disease. Nat Immunol 2001;2:108-15.

18 Gonzalo JA, Pan Y, Lloyd CM, Jia GQ, Yu G, Dussault B, et al. Mouse monocyte-derived chemokine is involved in airway hyperreactivity and lung inflammation. J Immunol 1999;163:403-11.

19 Tang HL, Cyster JG. Chemokine up-regulation and activated T cell attraction by maturing dendritic cells. Science 1999;284:819-22.

20 Baggiolini M. Chemokines and leukocyte traffic. Nature 1998;392:565-8.

21 Cyster JG. Chemokines and cell migration in secondary lymphoid organs. Science 1999;286:2098-102.

22 Campbell JJ, Brightling CE, Symon FA, Qin S, Murphy KE, Hodge M, et al. Expression of chemokine receptors by lung $T$ cells from normal and asthmatic subjects. J Immunol 2001;166:2842-8.
23 Zabel BA, Agace WW, Campbell JJ, Heath HM, Parent D, Roberts Al, et al. Human G protein-coupled receptor GPR-9-6/CC chemokine receptor 9 is selectively expressed on intestinal homing T lymphocytes, mucosal lymphocytes, and thymocytes and is required for thymus-expressed chemokine-mediated chemotaxis. J Exp Med 1999;190:1241-56.

24 Godessart N, Kunkel SL. Chemokines in autoimmune disease. Curr Opin Immunol 2001;13:670-5

25 Tak PP, Smeets TJ, Daha MR, Kluin PM, Meijers KA, Brand R, et al. Analysis of the synovial cell infiltrate in early rheumatoid synovial tissue in relation to local disease activity. Arthritis Rheum 1997;40:217-25.

26 Takemura S, Braun A, Crowson C, Kurtin PJ, Cofield RH, O'Fallon WM, et al. Lymphoid neogenesis in rheumatoid synovitis. J Immunol 2001; 167:1072-80

27 Shi K, Hayashida K, Kaneko M, Hashimoto J, Tomita T, Lipsky PE, et al. Lymphoid chemokine B cell-attracting chemokine-1 (CXCL13) is expressed in germinal center of ectopic lymphoid follicles within the synovium of chronic arthritis patients. J Immunol 2001;166:650-5.

28 Page G, Lebecque S, Miossec P. Anatomic localization of immature and mature dendritic cells in an ectopic lymphoid organ: correlation with selective chemokine expression in rheumatoid synovium. J Immunol 2002;168:5333-41.

29 Matsui T, Akahoshi T, Namai R, Hashimoto A, Kurihara Y, Rana M, et al Selective recruitment of CCR6-expressing cells by increased production of MIP-3 alpha in rheumatoid arthritis. Clin Exp Immunol 2001;125:155-61.

30 Ruth JH, Shahrara S, Park CC, Morel JC, Kumar P, Qin S, et al. Role of macrophage inflammatory protein-3alpha and its ligand CCR6 in rheumatoid arthritis. Lab Invest 2003;83:579-88.

31 Buckley CD, Amft N, Bradfield PF, Pilling D, Ross E, Arenzana-Seisdedos F, et al. Persistent induction of the chemokine receptor CXCR4 by TGF-beta 1 on synovial T cells contributes to their accumulation within the rheumatoid synovium. J Immunol 2000;165:3423-9.

32 Nanki T, Hayashida K, El Gabalawy HS, Suson S, Shi K, Girschick HJ, et al. Stromal cell-derived factor-1-CXC chemokine receptor 4 interactions play a central role in CD4+ T cell accumulation in rheumatoid arthritis synovium. $\mathrm{J}$ Immunol 2000; 165:6590-8.

33 Pablos JL, Santiago B, Galindo M, Torres C, Brehmer MT, Blanco FJ, et al. Synoviocyte-derived CXCL12 is displayed on endothelium and induces angiogenesis in rheumatoid arthritis. J Immunol 2003;170:21 47-52.

34 Nakayama T, Hieshima K, Izawa D, Tatsumi Y, Kanamaru A, Yoshie O. Cutting edge: profile of chemokine receptor expression on human plasma cells accounts for their efficient recruitment to target tissues. J Immunol 2003; 170:1136-40.

$35 \mathrm{Kim}$ CH, Kunkel EJ, Boisvert J, Johnston B, Campbell JJ, Genovese MC, et al. Bonzo/CXCR6 expression defines type 1-polarized T-cell subsets with extralymphoid tissue homing potential. J Clin Invest 2001;107:595-601.

36 Hosaka S, Akahoshi T, Wada C, Kondo H. Expression of the chemokine superfamily in rheumatoid arthritis. Clin Exp Immunol 1994;97:451-7.

37 Villiger PM, Terkeltaub R, Lotz M. Production of monocyte chemoattractant protein-1 by inflamed synovial tissue and cultured synoviocytes. J Immunol 1992; 149:722-7.

38 Koch AE, Kunkel SL, Burrows JC, Evanoff HL, Haines GK, Pope RM, et al. Synovial tissue macrophage as a source of the chemotactic cytokine IL-8. J Immunol 1991;147:2187-95.

39 Koch AE, Kunkel SL, Harlow LA, Mazarakis DD, Haines GK, Burdick MD, et al. Epithelial neutrophil activating peptide-78: a novel chemotactic cytokine for neutrophils in arthritis. J Clin Invest 1994;94:1012-18.

40 Butcher EC. Leukocyte-endothelial cell recognition: three (or more) steps to specificity and diversity. Cell 1991;67:1033-6.

41 Baggiolini M, Loetscher P, Moser B. Interleukin-8 and the chemokine family. Int J Immunopharmacol 1995; 17:103-8.

42 Koch AE, Kunkel SL, Burrows JC, Evanoff HL, Haines GK, Pope RM, et al. Synovial tissue macrophage as a source of the chemotactic cytokine IL-8. $\mathrm{J}$ Immunol 1991;147:2187-95.

43 Endo H, Akahoshi T, Takagishi K, Kashiwazaki S, Matsushima K. Elevation of interleukin-8 (IL-8) levels in joint fluids of patients with rheumatoid arthritis and the induction by IL-8 of leukocyte infiltration and synovitis in rabbit joints. Lymphokine Cytokine Res 1991;10:245-52.

44 Kraan MC, Patel DD, Haringman JJ, Smith MD, Weedon H, Ahern MJ, et al. The development of clinical signs of rheumatoid synovial inflammation is associated with increased synthesis of the chemokine CXCL8 (interleukin-8). Arthritis Res 2001;3:65-71

45 Hayashida K, Nanki T, Girschick H, Yavuz S, Ochi T, Lipsky PE. Synovial stromal cells from rheumatoid arthritis patients attract monocytes by producing MCP-1 and IL-8. Arthritis Res 2001;3:118-26.

46 Randolph GJ, Furie MB. A soluble gradient of endogenous monocyte chemoattractant protein-1 promotes the transendothelial migration of monocytes in vitro. J Immunol 1995;155:3610-18.

47 Gu L, Rutledge B, Fiorillo J, Ernst C, Grewal I, Flavell R, et al. In vivo properties of monocyte chemoattractant protein-1. J Leukoc Biol 1997;62:577-80.

48 Loetscher P, Seitz M, Clark-Lewis I, Baggiolini M, Moser B. Monocyte chemotactic proteins MCP-1, MCP-2, and MCP-3 are major attractants for human CD4+ and CD8+ T lymphocytes. FASEB J 1994;8:1055-60.

49 Koch AE, Kunkel SL, Harlow LA, Johnson B, Evanoff HL, Haines GK, et al. Enhanced production of monocyte chemoattractant protein-1 in rheumatoid arthritis. J Clin Invest 1992;90:772-9.

50 Akahoshi T, Wada C, Endo H, Hirota K, Hosaka S, Takagishi K, et al. Expression of monocyte chemotactic and activating factor in rheumatoid arthritis. Regulation of its production in synovial cells by interleukin-1 and tumor necrosis factor. Arthritis Rheum 1993;36:762-71. 
51 Rathanaswami P, Hachicha M, Sadick M, Schall TJ, McColl SR. Expression of the cytokine RANTES in human rheumatoid synovial fibroblasts. Differential regulation of RANTES and interleukin- 8 genes by inflammatory cytokines. J Biol Chem 1993;268:5834-9.

52 Robinson E, Keystone EC, Schall TJ, Gillett N, Fish EN. Chemokine expression in rheumatoid arthritis (RA): evidence of RANTES and macrophage inflammatory protein (MIP)-1 beta production by synovial T cells. Clin Exp Immunol 1995;101:398-407.

53 Hosaka S, Akahoshi T, Wada C, Kondo H. Expression of the chemokine superfamily in rheumatoid arthritis. Clin Exp Immunol 1994;97:451-7.

54 Volin MV, Shah MR, Tokuhira M, Haines GK, Woods JM, Koch AE. RANTES expression and contribution to monocyte chemotaxis in arthritis. Clin Immunol Immunopathol 1998;89:44-53.

55 Shadidi KR, Thompson KM, Henriksen JE, Natvig JB, Aarvak T. Association of antigen specificity and migratory capacity of memory $T$ cells in rheumatoid arthritis. Scand J Immunol 2002;55:274-83.

56 Qin S, Rottman JB, Myers P, Kassam N, Weinblatt M, Loetscher M, et al. The chemokine receptors CXCR3 and CCR5 mark subsets of T cells associated with certain inflammatory reactions. J Clin Invest 1998;101:746-54.

57 Sallusto F, Lenig D, Mackay CR, Lanzavecchia A. Flexible programs of chemokine receptor expression on human polarized T helper 1 and 2 lymphocytes. J Exp Med 1998;187:875-83.

58 Sallusto F, Lanzavecchia A, Mackay CR. Chemokines and chemokine receptors in T-cell priming and Th1/Th2-mediated responses. Immunol Today 1998; 19:568-74.

59 Loetscher P, Uguccioni M, Bordoli L, Baggiolini M, Moser B, Chizzolini C, et al. CCR5 is characteristic of Th1 lymphocytes. Nature 1998;391:344-5.

60 Patel DD, Zachariah JP, Whichard LP. CXCR3 and CCR5 ligands in rheumatoid arthritis synovium. Clin Immunol 2001;98:39-45.

61 Mohan K, Ding Z, Hanly J, Issekutz TB. IFN-gamma-inducible T cell alpha chemoattractant is a potent stimulator of normal human blood T lymphocyte transendothelial migration: differential regulation by IFN-gamma and TNFalpha. J Immunol 2002;168:6420-8.

62 Koch AE, Kunkel SL, Harlow LA, Mazarakis DD, Haines GK, Burdick MD, et al. Macrophage inflammatory protein-1 alpha. A novel chemotactic cytokine for macrophages in rheumatoid arthritis. J Clin Invest 1994;93:921-8

63 al-Mughales J, Blyth TH, Hunter JA, Wilkinson PC. The chemoattractant activity of rheumatoid synovial fluid for human lymphocytes is due to multiple cyłokines. Clin Exp Immunol 1996; 106:230-6.

64 Patel DD, Koopmann W, Imai T, Whichard LP, Yoshie O, Krangel MS. Chemokines have diverse abilities to form solid phase gradients. Clin Immunol 2001;99:43-52

65 Constantin G, Majeed M, Giagulli C, Piccio L, Kim JY, Butcher EC, et al. Chemokines trigger immediate beta2 integrin affinity and mobility changes: differential regulation and roles in lymphocyte arrest under flow. Immunity 2000;13:759-69.

66 Chan JR, Hyduk SJ, Cybulsky MI. Chemoattractants induce a rapid and transient upregulation of monocyte alpha4 integrin affinity for vascular cell adhesion molecule 1 which mediates arrest: an early step in the process of emigration. J Exp Med 2001;193:1149-58.

67 Weber C. Novel mechanistic concepts for the control of leukocyte transmigration: specialization of integrins, chemokines, and junctional molecules. J Mol Med 2003;81:4-19.

68 Gerszten RE, Garcia-Zepeda EA, Lim YC, Yoshida M, Ding HA Gimbrone MA Jr, et al. MCP-1 and IL-8 trigger firm adhesion of monocytes to vascular endothelium under flow conditions. Nature 1999;398:718-23.

69 Weber C, Weber KS, Klier C, Gu S, Wank R, Horuk R, et al. Specialized roles of the chemokine receptors CCRI and CCR5 in the recruitment of monocytes and $T(H) 1$-like/CD45RO(+) T cells. Blood 2001;97:1144-6.

70 Piali L, Weber C, LaRosa G, Mackay CR, Springer TA, Clark-Lewis I, et al. The chemokine receptor CXCR3 mediates rapid and shear-resistant adhesion-induction of effector T lymphocytes by the chemokines IP10 and Mig. Eur J Immunol 1998;28:961-72.

71 Corrigall VM, Arastu M, Khan S, Shah C, Fife M, Smeets T, et al. Functional IL-2 receptor beta (CDI22) and gamma (CDI32) chains are expressed by fibroblast-like synoviocytes: activation by IL-2 stimulates monocyte chemoattractant protein-1 production. J Immunol 2001;166:4141-7.

72 Monaco C, Andreakos E, Young S, Feldmann M, Paleolog E. T cell-mediated signaling to vascular endothelium: induction of cytokines, chemokines, and tissue factor. J Leukoc Biol 2002;71:659-68.

73 Hachicha M, Rathanaswami P, Schall TJ, McColl SR. Production of monocyte chemotactic protein-1 in human type B synoviocytes. Synergistic effect of tumor necrosis factor alpha and interferon-gamma. Arthritis Rheum 1993;36:26-34.

74 Robinson E, Keystone EC, Schall TJ, Gillett N, Fish EN. Chemokine expression in rheumatoid arthritis (RA): evidence of RANTES and macrophage inflammatory protein (MIP)-1 beta production by synovial $T$ cells. Clin Exp Immunol 1995;101:398-407.

75 Nanki T, Nagasaka K, Hayashida K, Saita Y, Miyasaka N. Chemokines regulate IL- 6 and IL- 8 production by fibroblast-like synoviocytes from patients with rheumatoid arthritis. J Immunol 2001;167:5381-5.

76 Fahey TJ, III, Tracey KJ, Tekamp-Olson P, Cousens LS, Jones WG, Shires GT, et al. Macrophage inflammatory protein 1 modulates macrophage function. J Immunol 1992;148:2764-9.

77 Kanbe K, Takagishi K, Chen Q. Stimulation of matrix metalloprotease 3 release from human chondrocytes by the interaction of stromal cell-derived factor 1 and CXC chemokine receptor 4. Arthritis Rheum 2002;46:130-7.

78 Borzi RM, Mazzetti I, Cattini L, Uguccioni M, Baggiolini M, Facchini A. Human chondrocytes express functional chemokine receptors and release matrix-degrading enzymes in response to $\mathrm{C}-\mathrm{X}-\mathrm{C}$ and $\mathrm{C}-\mathrm{C}$ chemokines. Arthritis Rheum 2000;43:1734-41.

79 Folkman J. Angiogenesis in cancer, vascular, rheumatoid and other disease. Nat Med 1995:1:27-31.

80 Strieter RM, Polverini PJ, Kunkel SL, Arenberg DA, Burdick MD, Kasper J et al. The functional role of the ELR motif in CXC chemokine-mediated angiogenesis. J Biol Chem 1995;270:27348-57.

81 Szekanecz Z, Koch AE. Chemokines and angiogenesis. Curr Opin Rheumatol 2001;13:202-8

82 Koch AE, Volin MV, Woods JM, Kunkel SL, Connors MA, Harlow LA, et al. Regulation of angiogenesis by the C-X-C chemokines interleukin- 8 and epithelial neutrophil activating peptide 78 in the rheumatoid joint. Arthritis Rheum 2001;44:31-40.

83 Romagnani P, Annunziato F, Lasagni L, Lazzeri E, Beltrame C, Francalanci $M$, et al. Cell cycle-dependent expression of CXC chemokine receptor 3 by endothelial cells mediates angiostatic activity. J Clin Invest 2001; 107:53-63.

84 Salcedo R, Resau JH, Halverson D, Hudson EA, Dambach M, Powell D, et al. Differential expression and responsiveness of chemokine receptors (CXCR)3 ) by human microvascular endothelial cells and umbilical vein endothelial cells. FASEB J 2000;14:2055-64.

85 Cao Y, Chen C, Weatherbee JA, Tsang M, Folkman J. gro-beta, a -C-X-Cchemokine, is an angiogenesis inhibitor that suppresses the growth of Lewis lung carcinoma in mice. J Exp Med 1995;182:2069-77.

86 Salcedo R, Wasserman K, Young HA, Grimm MC, Howard OM, Anver MR, et al. Vascular endothelial growth factor and basic fibroblast growth factor induce expression of CXCR4 on human endothelial cells: in vivo neovascularization induced by stromal-derived factor-lalpha. Am J Pathol 1999;154:1125-35

87 Volin MV, Woods JM, Amin MA, Connors MA, Harlow LA, Koch AE. Fractalkine: a novel angiogenic chemokine in rheumatoid arthritis. Am J Pathol 2001;159:1521-30.

88 Ruth JH, Volin MV, Haines GK III, Woodruff DC, Katschke KJ Jr, Woods JM, et al. Fractalkine, a novel chemokine in rheumatoid arthritis and in rat adjuvant-induced arthritis. Arthritis Rheum 2001;44:1568-81.

89 Salcedo R, Ponce ML, Young HA, Wasserman K, Ward JM, Kleinman HK et al. Human endothelial cells express CCR2 and respond to MCP-1: direct role of MCP-1 in angiogenesis and tumor progression. Blood 2000;96:34-40.

90 Addison CL, Daniel TO, Burdick MD, Liu H, Ehlert JE, Xue YY, et al. The CXC chemokine receptor 2, CXCR2, is the putative receptor for ELR+ CXC chemokine-induced angiogenic activity. J Immunol 2000; 165:5269-77.

91 Kraan MC, Haringman JJ, Post WJ, Versendaal J, Breedveld FC, Tak PP. Immunohistological analysis of synovial tissue for differential diagnosis in early arthritis. Rheumatology (Oxford) 1999:38:1074-80.

92 Haywood L, McWilliams DF, Pearson Cl, Gill SE, Ganesan A, Wilson D, et al. Inflammation and angiogenesis in osteoarthritis. Arthritis Rheum 2003;48:2173-7.

93 Smith MD, Triantafillou S, Parker A, Youssef PP, Coleman M. Synovial membrane inflammation and cytokine production in patients with early osteoarthritis. J Rheumatol 1997;24:365-71.

94 Conti P, Reale M, Barbacane RC, Castellani ML, Orso C. Differential production of RANTES and MCP-1 in synovial fluid from the inflamed human knee. Immunol Lett 2002;80:105-11.

95 Konig A, Krenn V, Toksoy A, Gerhard N, Gillitzer R. Mig, GRO alpha and RANTES messenger RNA expression in lining layer, infiltrates and different leucocyte populations of synovial tissue from patients with rheumatoid arthritis, psoriatic arthritis and osteoarthritis. Virchows Arch 2000;436:449-58

96 Koch AE, Kunkel SL, Harlow LA, Johnson B, Evanoff HL, Haines GK, et al. Enhanced production of monocyte chemoattractant protein-1 in rheumatoid arthritis. J Clin Invest 1992;90:772-9.

97 Seitz M, Loetscher P, Dewald B, Towbin H, Ceska M, Baggiolini M. Production of interleukin-1 receptor antagonist, inflammatory chemotactic proteins, and prostaglandin E by rheumatoid and osteoarthritic synoviocytes - regulation by IFN-gamma and IL-4. J Immunol 1994; 152:2060-5.

98 Koch AE, Kunkel SL, Shah MR, Fu R, Mazarakis DD, Haines GK, et al. Macrophage inflammatory protein-1 beta: a C-C chemokine in osteoarthritis. Clin Immunol Immunopathol 1995;77:307-14.

99 Borzi RM, Mazzetti I, Macor S, Silvestri T, Bassi A, Cattini L, et al. Flow cytometric analysis of intracellular chemokines in chondrocytes in vivo: constitutive expression and enhancement in osteoarthritis and rheumatoid arthritis. FEBS Lett 1999;455:238-42.

100 Yuan GH, Masuko-Hongo K, Sakata M, Tsuruha J, Onuma H, Nakamura H, et al. The role of $\mathrm{C}-\mathrm{C}$ chemokines and their receptors in osteoarthritis. Arthritis Rheum 2001;44:1056-70.

101 Silvestri T, Meliconi R, Pulsatelli L, Dolzani P, Zizzi F, Frizziero L, et al. Downmodulation of chemokine receptor cartilage expression in inflammatory arthritis. Rheumatology (Oxford) 2003;42:14-18.

102 Ross EL, D'Cruz D, Morrow WJ. Localized monocyte chemotactic protein-1 production correlates with $T$ cell infiltration of synovium in patients with psoriatic arthritis. J Rheumatol 2000;27:2432-43.

103 Mack M, Bruhl H, Gruber R, Jaeger C, Cihak J, Eiter V, et al. Predominance of mononuclear cells expressing the chemokine receptor CCR5 in synovial effusions of patients with different forms of arthritis. Arthritis Rheum 1999;42:981-8.

104 Konig A, Krenn V, Gillitzer R, Glockner J, Janssen E, Gohlke F, et al. Inflammatory infiltrate and interleukin-8 expression in the synovium of psoriatic arthritis - an immunohistochemical and mRNA analysis. Rheumatol Int 1997;17):159-68. 
105 Thornton S, Duwel LE, Boivin GP, Ma Y, Hirsch R. Association of the course of collagen-induced arthritis with distinct patterns of cytokine and chemokine messenger RNA expression. Arthritis Rheum 1999;42:1109-18.

106 Szekanecz Z, Halloran MM, Volin MV, Woods JM, Strieter RM, Kenneth HG III, et al. Temporal expression of inflammatory cytokines and chemokines in rat adjuvant-induced arthritis. Arthritis Rheum 2000;43:1266-77.

107 Ogata H, Takeya M, Yoshimura T, Takagi K, Takahashi K. The role of monocyte chemoattractant protein-1 (MCP-1) in the pathogenesis of collagen-induced arthritis in rats. J Pathol 1997; 182:106-14.

108 Gong JH, Ratkay LG, Waterfield JD, Clark-Lewis I. An antagonist of monocyte chemoattractant protein 1 (MCP-1) inhibits arthritis in the MRL-Ipr mouse model. J Exp Med 1997; 186:131-7.

109 Barnes DA, Tse J, Kaufhold M, Owen M, Hesselgesser J, Strieter R, et al. Polyclonal antibody directed against human RANTES ameliorates disease in the Lewis rat adjuvant-induced arthritis model. J Clin Invest 1998;101:2910-19.

110 Plater-Zyberk C, Hoogewerf AJ, Proudfoot AE, Power CA, Wells TN. Effect of a CC chemokine receptor antagonist on collagen induced arthritis in DBA/1 mice. Immunol Lett 1997; 57:117-20.

111 Salomon I, Netzer N, Wildbaum G, Schif-Zuck S, Maor G, Karin N. Targeting the function of IFN-gamma-inducible protein 10 suppresses ongoing adjuvant arthritis. J Immunol 2002;169:2685-93.

112 Halloran MM, Woods JM, Strieter RM, Szekanecz Z, Volin MV, Hosaka S et al. The role of an epithelial neutrophil-activating peptide-78-like protein in rat adjuvant-induced arthritis. J Immunol 1999;162:7492-500.

113 Matthys P, Hatse S, Vermeire K, Wuyts A, Bridger G, Henson GW, et al. AMD3100, a potent and specific antagonist of the stromal cell-derived factor-1 chemokine receptor CXCR4, inhibits autoimmune joint inflammation in IFN-gamma receptor-deficient mice. J Immunol 2001; 167:4686-92.
114 Podolin PL, Bolognese BJ, Foley JJ, Schmidt DB, Buckley PT, Widdowson KL, et al. A potent and selective nonpeptide antagonist of CXCR2 inhibits acute and chronic models of arthritis in the rabbit. J Immunol 2002;169:6435-44.

115 Yang YF, Mukai T, Gao P, Yamaguchi N, Ono S, Iwaki H, et al. A nonpeptide CCR5 antagonist inhibits collagen-induced arthritis by modulating $T$ cell migration without affecting anti-collagen T cell responses. Eur J Immunol 2002;32:21 24-32.

116 Gladue RP, Tylaska LA, Brissette WH, Lira PD, Kath JC, Poss CS, et al. CP481,715 , a potent and selective CCR1 antagonist with potential therapeutic implications for inflammatory diseases. J Biol Chem 2003;278:40473-80.

117 Carter PH. Chemokine receptor antagonism as an approach to antiinflammatory therapy: 'just right' or plain wrong? Curr Opin Chem Biol 2002;6:510-25.

118 Keystone EC. Abandoned therapies and unpublished trials in rheumatoid arthritis. Curr Opin Rheumatol 2003;15:253-8.

119 Haringman JJ, Kraan MC, Smeets TJ, Zwinderman KH, Tak PP. Chemokine blockade and chronic inflammatory disease: proof of concept in patients with rheumatoid arthritis. Ann Rheum Dis 2003:62:715-21.

120 Rottman JB, Slavin AJ, Silva R, Weiner HL, Gerard CG, Hancock WW. Leukocyte recruitment during onset of experimental allergic

encephalomyelitis is CCR1 dependent. Eur J Immunol 2000;30:2372-7.

121 Chuntharapai A, Kim KJ. Regulation of the expression of IL-8 receptor A/B by IL-8: possible functions of each receptor. J Immunol 1995:155:2587-94.

122 Katschke KJ Jr, Rottman JB, Ruth JH, Qin S, Wu L, LaRosa G, et al. Differential expression of chemokine receptors on peripheral blood, synovial fluid, and synovial tissue monocytes/macrophages in rheumatoid arthritis. Arthritis Rheum 2001;44:1022-32.

123 Xanthou G, Duchesnes CE, Williams TJ, Pease JE. CCR3 functional responses are regulated by both CXCR3 and its ligands CXCL9, CXCL10 and CXCL1 1. Eur J Immunol 2003;33:2241-50. 